\title{
Educational Video for Infant Diarrhea Prevention: Randomized Clinical Trial ORIGINAL
}

Emanuella Silva Joventino', Ádria Marcela Vieira Ferreira², Ana Lúcia Araújo Gomes ${ }^{3}$, Fabiane do Amaral Gubert ${ }^{3}$, Jardeliny Corrêa da Penha ${ }^{3}$, Leidiane Minervina Moraes de Sabino ${ }^{4}$, Ludmila Alves do Nascimento4, Maria de Fátima Pereira de Sousa Galvão5, Paulo César de Almeida ${ }^{6}$, Lorena Barbosa Ximenes ${ }^{7}$

\section{Abstract}

Introduction: Diarrhea is a major cause of illness in children under five years of age and, along with pneumonia, is a major cause of child mortality. Through behavioral influence on the occurrence of diarrhea, health education is an important facilitator for empowering individuals, families and communities, contributing to the promotion of health and, consequently, to reduce cases of childhood diarrhea. Therefore, this study aimed to evaluate the effect of the educational video "Infant Diarrhea: you are able to prevent" on mothers of children under five years of age, according to the aspects related to the care of children's health and the occurrence of infant diarrhea.

Methods: Randomized clinical trial, conducted in Fortaleza, Ceará, Brazil, with 133 mothers of children under five years of age, with 70 allocated in the comparison group and 63 in the intervention group. Data collection took place from April to June 2013, in two moments: the first in the Unit of Primary Health Care and the second by telephone after two months.

Results: The groups were similar in all sociodemographic aspects analyzed ( $p>0.196)$. Moreover, there was no statistically significant association between the occurrence of infant diarrhea and the characteristics related to the care of children's health. The chance for occurrence of diarrhea showed up higher in the comparison group $(O R>1)$ with respect to four of the variables: exclusive breastfeeding, bottle-feeding, how they clean the bottle and if they boil/scald other utensils used in the child's diet.
1 Registered Nurse. PhD in Nursing. Professor at the University of International Integration of AfricanBrazilian Lusophony, Brazil.

2 Registered Nurse. Student at the PhD in Nursing Program at the Federal University of Ceará, , Brazil.

3 Registered Nurse. Student at the PhD in Nursing Program at the Federal University of Ceará, UFC, Brazil. Professor at the Federal University of Piauí, Brazil.

4 Registered Nurse. Student at the PhD in Nursing Program at the Federal University of Ceará, Brazil

5 Registered Nurse. Master in Nursing Program at the Federal University of Ceará, Brazil.

6 Statistical. PhD in Public Health. Professor at the University State of Ceará, Brazil.

7 Registered Nurse. PhD in Nursing. Professor at the UFC, Brazil. Researcher at the National Counsel of Technological and Scientific Development.

Contact information:

Leidiane Minervina Moraes de Sabino.

Address: Avenida Senador Fernandes Tavora, 101, Apartment 210, Bairro Jockey Club. CEP: 60510-290. Fortaleza, Ceará, Brazil.

Tel: +55 (85) 99639.6883 .

ほ leidinhamoraes@hotmail.com 
Conclusion: The educational video was effective in promoting the adoption of healthy habits by the mothers and reducing chances of occurrence of infant diarrhea. It is essential that health professionals get to know the mentioned video and that this one guide the practice of these professionals in preventing infant diarrhea and empowering of mothers, so that they are able to also prevent the occurrence of this disease in their children.

\section{Keywords}

Health Education; Child

health; Diarrhea; Infantile.

\section{Introduction}

Diarrhea is a major cause of illness in children under five years of age [1] and, along with pneumonia, is a major cause of child mortality, accounting for $29 \%$, i.e. 2 million of all deaths of children worldwide [2].

The occurrence or the prevention of infant diarrhea may be associated with socioeconomic and health/environmental factors [3], as well as with aspects related to the care and health of the child, such as exclusive breastfeeding [4], rotavirus infection [5], use of bottle [6] and proper cleaning of the tools used in infant feeding [7].

Through behavioral influence on the occurrence of diarrhea, health education is an important facilitator for empowering individuals, families and communities, contributing to the promotion of health [8] and, consequently, to reduce cases of childhood diarrhea. Accordingly, the maternal role stands out in the prevention of this disease, since children are predominantly cared for by their mothers [9].

Therefore, the use of educational technologies that seek to encourage the development of maternal skills can be effective in children's health promotion and in the prevention of infant diseases. Educational videos have been widely used in health education activities, because they have a language suitable to their audience, being able to raise awareness among social groups to change their behaviors front to health problems [10].
Several studies identified the effectiveness of audiovisual resources. Such as a randomized clinical trial, developed in the State of Ceará, Brazil, which used a video about promoting secure attachment between seropositive mothers for human immunodeficiency virus and their children [11]; quasiexperimental study, in rural area of Bangalore, India, using a video that addressed the prevention and management of infant dehydration, having as public mothers of children under five years of age [12]; a quantitative-qualitative research, which used an audiovisual resource addressing maternal and neonatal health, being presented for men and women from Ethiopia [13]; and another randomized clinical trial, conducted in four rural counties in the State of Oregon, USA, with a video on promoting maternal oral health and prevention of caries in children [14].

Thus, the use of educational videos can increase the confidence of mothers in preventing infant diarrhea and assist them in caring for their child, influencing consequently in reducing the incidence of childhood diarrhea.

Therefore, this study aimed to evaluate the effect of the educational video "Infant Diarrhea: you are able to prevent" [15] on mothers of children under five years of age, according to the aspects related to the care of children's health and the occurrence of infant diarrhea. 


\section{Methods}

\section{Study design}

Randomized clinical trial (RCT) conducted with two groups, comparison and intervention.

\section{Scenario and sample}

Study conducted in two districts belonging to a Primary Health Care Unit (UAPS) of the Regional Executive Secretariat $V($ SER V) in Fortaleza (CE), located in Northeastern Brazil. Both districts have Human Development Index (HDI) considered to be low, between 0.338 and 0.446 , and are deprived of basic social facilities, such as adequate housing, sanitation, education, employment and income. [16]

The sample size was pre-determined using the formula for studies of comparative groups of two experimental means with bilateral test [17]. Thus, participated in the study 133 mothers of children under five years of age, being 70 in the comparison group (CG) and 63 in the intervention group (IG).

Grouped randomization with allocation of each district in one of the groups (intervention or comparison) occurred by simple assortment. Thus, mothers living in the $X$ district were allocated to $C G$ and mothers from the district $Y$ in IG.

The inclusion criteria were: mothers with at least one child under the age of five years, who were registered and tracked in the child welfare service in the UAPS. We excluded those possessing any cognitive limitations preventing them from participating in the educational intervention or answering the used scale, or had no telephone number for contact.

Mothers who met the selection criteria of the study were previously invited by the community health workers to attend on certain days at the UAPS. Both groups attended the place at different times in order to prevent the sharing of information between them.

\section{Data collection and intervention}

Data collection took place from April to June 2013 in two moments: M0 (first meeting) and M1 (two months after the first meeting). The MO happened in the UAPS, with the administration of one form addressing children's health-related care and another investigating the occurrence of infant diarrhea [18], both applied by a team of researchers. Infant diarrhea is characterized as the occurrence of three or more watery stools in a 24-hour interval [19].

In addition, mothers in the IG watched, in MO, the educational video "Infant Diarrhea: you are able to prevent" [15], which was administered only by the main researcher, in order to maintain blinding. This visual aid was developed based on the principles of the Theory of Self-efficacy [20] and it highlights situations in which mothers demonstrate how to prevent diarrhea in their children even in simpler environmental, socioeconomic and health conditions; moreover, it also highlights experiences of the mothers and instructions given by nurses to assist mothers to be able to increase their self-efficacy in preventing infant diarrhea in their children [21].

The M1 happened by telephone and we used a reduced form to investigate the occurrence of infant diarrhea, with objective and multiple choice questions, which were presented by a previously trained interviewer.

It is noteworthy that this moment took place after two months of the first meeting.

\section{Outcome measure}

The outcome variable was the decrease in the occurrence of infant diarrhea, investigated by applying the reduced form. This instrument comprised questions about the occurrence or not of infant diarrhea. Also, if the child had diarrhea, the mother was asked about the stool characteristics, additional symptoms, such as signs and symptoms of dehydration, looking for some health service, hospitalization of the child, use of medication, conducting homema- 
de recipes (homemade oral rehydration solution, tea and constipating fruits), use and preparation of the oral rehydration solution, guidelines provided by health professionals, among others.

\section{Statistical Analysis}

The data were processed using the SPSS 20, license number 10101131007. We compared the sociodemographic characteristics of the two groups using the chi-square test. The analysis of the occurrence of infant diarrhea, according to the variables related to children's health and moments, was made through Odds Ratio (OD) and its Confidence Interval (Cl) $95 \%$. It was considered as statistically significant $\mathrm{p}<0,05$.

\section{Ethical Aspects}

The study was approved by the Research Ethics Committee of the Federal University of the Ceará under protocol No. 106/12. The signatures of the mothers were obtained in the Declaration of Free and Clarified Consent, to ensure anonymity, the freedom to continue or not participating in the research and clarification of the relevance of their participation.

\section{Results}

It can be observed by Table 1 that the groups were similar in all sociodemographic aspects analyzed ( $p>0.196$ ). Thus, it was predominant among the groups: maternal age between 19 and 29 years, maternal education of 5-8 years of study, women with a partner and house workers, number of residents in the house between 4 and 5 and per capita income equal or higher than 1 minimum wage.

Table 2 shows the chance of occurrence of infant diarrhea, according to the characteristics related to children's health and the monitoring moments (MO - before the intervention and M1 - after the educational intervention) of the control group (CG) and intervention (IG).
Table 1. Distribution of mothers according to the group and sociodemographic characteristics. Fortaleza, Ceará, Brazil, 2016.

\begin{tabular}{|c|c|c|c|c|c|}
\hline \multirow[t]{2}{*}{ Variables } & \multicolumn{2}{|c|}{$\begin{array}{c}\text { Comparison } \\
\text { Group }\end{array}$} & \multicolumn{2}{|c|}{$\begin{array}{c}\text { Intervention } \\
\text { Group }\end{array}$} & \multirow{2}{*}{ value $^{p}$} \\
\hline & $\mathrm{N}$ & $\%$ & $\mathrm{~N}$ & $\%$ & \\
\hline \multicolumn{6}{|c|}{ Maternal age (years) } \\
\hline $15-18$ & 5 & 5.6 & 8 & 8.9 & \multirow{4}{*}{.708} \\
\hline $19-29$ & 44 & 48.9 & 47 & 52.2 & \\
\hline $30-39$ & 33 & 36.7 & 27 & 30.0 & \\
\hline $40-58$ & 8 & 8.9 & 8 & 8.9 & \\
\hline \multicolumn{6}{|c|}{ Maternal Education (years of study) } \\
\hline $1-4$ & 9 & 10.0 & 12 & 13.3 & \multirow{3}{*}{.300} \\
\hline $5-8$ & 41 & 45.6 & 48 & 53.3 & \\
\hline $9-11$ & 40 & 44.4 & 30 & 33.3 & \\
\hline \multicolumn{6}{|l|}{ Marital Status } \\
\hline With partner & 56 & 62.2 & 59 & 66.3 & \multirow{2}{*}{.570} \\
\hline Without a partner & 34 & 37.8 & 30 & 33.7 & \\
\hline \multicolumn{6}{|l|}{ Occupation } \\
\hline House Workers & 64 & 71.1 & 67 & 74.4 & \multirow{2}{*}{.615} \\
\hline Others & 26 & 28.9 & 23 & 25.6 & \\
\hline \multicolumn{6}{|l|}{ Child's Gender } \\
\hline Male & 47 & 52.2 & 55 & 61.8 & \multirow{2}{*}{.196} \\
\hline Female & 43 & 47.8 & 34 & 38.2 & \\
\hline \multicolumn{6}{|c|}{ Number of residents } \\
\hline 2 a 3 & 28 & 31.1 & 30 & 33.3 & \multirow{3}{*}{.756} \\
\hline 4 a 5 & 42 & 46.7 & 44 & 48.9 & \\
\hline 6 a 11 & 20 & 22.2 & 16 & 17.8 & \\
\hline \multicolumn{6}{|c|}{ Per capita income ${ }^{b}(R \$)$} \\
\hline $70-169,50$ & 5 & 5.6 & 6 & 6.9 & \multirow{4}{*}{.542} \\
\hline $169,51-339$ & 15 & 16.7 & 13 & 14.9 & \\
\hline $340-678$ & 24 & 26.7 & 16 & 18.4 & \\
\hline $679-2840$ & 46 & 51.1 & 52 & 59.8 & \\
\hline \multicolumn{6}{|l|}{ Number of children } \\
\hline 1 & 29 & 32.6 & 33 & 37.1 & \multirow{4}{*}{.801} \\
\hline 2 & 30 & 33.7 & 22 & 24.7 & \\
\hline 3 a 4 & 26 & 29.2 & 33 & 37.1 & \\
\hline 5 a 8 & 4 & 4.5 & 1 & 1.1 & \\
\hline
\end{tabular}


Table 2. Evaluation of odds ratio of infant diarrhea according to the aspects related to the care and health of the child. Fortaleza, Ceará, Brazil, 2016.

\begin{tabular}{|c|c|c|c|c|c|c|c|c|c|c|c|c|c|}
\hline \multirow{3}{*}{ Variables } & \multicolumn{4}{|c|}{$\begin{array}{l}\text { Occurrence of Diarrhea } \\
\text { (M0) }\end{array}$} & \multicolumn{2}{|c|}{ RC } & \multirow{3}{*}{$\begin{array}{l}p- \\
\text { valor* }\end{array}$} & \multicolumn{4}{|c|}{$\begin{array}{l}\text { Occurrence of Diarrhea } \\
\text { (M1) }\end{array}$} & \multicolumn{2}{|c|}{ RC } \\
\hline & \multicolumn{2}{|c|}{ CG } & \multicolumn{2}{|c|}{ IG } & \multirow{2}{*}{$\mathrm{RC}$} & \multirow{2}{*}{$\begin{array}{c}\text { IC } \\
95 \%\end{array}$} & & \multicolumn{2}{|c|}{$C G$} & \multicolumn{2}{|c|}{ IG } & \multirow{2}{*}{$\mathrm{RC}$} & \multirow{2}{*}{$\begin{array}{c}\text { IC } \\
95 \%\end{array}$} \\
\hline & $\mathrm{N}$ & $\%$ & N & $\%$ & & & & $\mathrm{~N}$ & $\%$ & $\mathrm{~N}$ & $\%$ & & \\
\hline
\end{tabular}

Exclusive Breastfeedingmonths)

\begin{tabular}{|l|c|c|c|c|c|c|c|c|c|c|c|c|c|}
\hline$<6$ & 61 & 87.1 & 47 & 74.6 & 2.30 & $0.93-5.68$ & 0.065 & 10 & 90.9 & 7 & 77.8 & 2.85 & $0.21-37.99$ \\
\hline$=6$ & 9 & 12.9 & 16 & 25.4 & & 1.00 & & 1 & 9.1 & 2 & 22.2 & & 1.00 \\
\hline
\end{tabular}

Rotavirus Vaccine

\begin{tabular}{|l|c|c|c|c|c|c|c|c|c|c|c|}
\hline No & 3 & 4.3 & 5 & 8.1 & 0.51 & $0.11-2.26$ & 0.375 & 1 & 8.3 & 0 & 0 \\
\hline Yes & 66 & 95.7 & 57 & 91.9 & & 1.00 & & 11 & 91.7 & 8 & 100.0 \\
\hline
\end{tabular}

Bottle utilization in the child's diet

\begin{tabular}{|l|l|l|l|l|l|l|l|l|l|l|l|l|}
\hline Yes & 31 & 44.3 & 35 & 54.7 & 0.7 & $0.33-1.30$ & 8 & 66.7 & 5 & 55.6 & 1.60 & $0.27-9.49$ \\
\hline No & 39 & 55.7 & 29 & 45.3 & & 1.00 & 4 & 33.3 & 4 & 44.0 & 1.0 \\
\hline
\end{tabular}

Way of cleaning the bottle after use

\begin{tabular}{|c|c|c|c|c|c|c|c|c|c|c|c|c|c|}
\hline $\begin{array}{l}\text { Washes } \\
\text { with water }\end{array}$ & 14 & 41.2 & 10 & 29.4 & 1.68 & $0.61-4.59$ & \multirow{2}{*}{0.310} & 3 & 37.5 & 2 & 40.0 & 0.90 & $0.09-8.89$ \\
\hline Boil/Scald & 20 & 58.8 & 24 & 70.6 & & 1.00 & & 5 & 62.5 & 3 & 60.0 & & 1.0 \\
\hline \multicolumn{14}{|c|}{ Boil/Scald the utensils used in the child's diet } \\
\hline No & 39 & 55.7 & 34 & 55.7 & 0.99 & $0.50-1.99$ & \multirow{2}{*}{1.000} & 7 & 58.3 & 2 & 22.2 & .90 & $0.70-34.30$ \\
\hline Yes & 31 & 44.3 & 27 & 44.3 & & 1.00 & & 5 & 41.7 & 7 & 77.8 & & 1.0 \\
\hline
\end{tabular}

Despite of not having a statistically significant association between the occurrence of infant diarrhea and the characteristics studied, it can be observed that the chance for occurrence of diarrhea showed up higher in $C G(O R>1)$, associated with the variables:

The chance of the children who were exclusively breastfed less than six months to have diarrhea in MO in CG was 2.30 times higher than in the IG, compared with those who were breastfed for six months. Related to $M 1$, it can be seen that the chance continued higher in CG and even increased to 2.85 times.

In turn, the rotavirus vaccine showed no difference in chances for the occurrence of diarrhea in children in the two groups $(O R<1.0)$ on both moments.

Note that the chance of occurrence of diarrhea among those who used a bottle in the child's diet in
M1, after two months of educational intervention, was 1.60 times higher in CG than in IG.

Regarding the cleaning of the bottle after use, it can also be found that in $\mathrm{MO}$, the chance of occurrence of diarrhea in children whose mothers just washed with soap and water was 1.68 times higher in the CG than in the IG.

Still, it can be observed that regarding to mothers who did not boil/scald the utensils used in the child's diet, the chance of diarrhea in children in the CG, in M1, was 4.90 times higher than in the IG.

\section{Discussion}

The occurrence of diarrhea is usually associated with low educational level of the child's caregiver, illiterate or under 8 years of education [6, 9, 22]; mothers aged 20 to 29 years [22] and house workers [23]; 
and families with family income below a minimum wage [6]. These characteristics, mostly, are similar to the mothers of children with diarrhea in this study, although the income of the majority of mothers was higher than the minimum wage (between $\mathrm{R} \$$ 679.00 and $R \$ 2840.00$ ).

Regarding the occurrence of diarrhea associated with the variable exclusive breastfeeding, it can be seen that in both groups, most children with diarrhea were exclusively breastfed for less than six months. A research conducted in Qatar, to determine the relation between breastfeeding and diarrhea, found that from the 1278 newborns investigated, the risk for diarrhea was higher in children fed with infant formula (48.7\%) and in those who were partially breastfed (37.3\%) when compared to those who were exclusively breastfed (32.5\%) [4].

In addition, the chance of children exclusively breastfed for less than six months have diarrhea was 2.30 times (M0) and 2.85 times (M1) higher in CG than in IG. It is noteworthy that in the educational video "Diarrhea: you are able to prevent", in addition to stimulating the exclusive breastfeeding for 6 months in order to prevent infant diarrhea, healthy habits are especially encouraged to be adopted, such as washing hands with water and soap, soaking fruits and vegetables in sodium hypochlorite or bleach, cleaning household items and the place where the food is prepared, disposal of household waste, healthy nutrition, up-to-date vaccination, among others [24].

Thus, it is understood that, regardless of the majority of children, in both groups the CG and $I G$, have been breastfed for less time than recommended, the mothers of the IG possibly were more confident about adopting preventive care against diarrhea after watching the video, therefore minimizing the risk of the occurrence of diarrhea two months after the educational intervention.

Regarding the oral human rotavirus vaccine (OHRV), it is noted, in both groups, that the majo- rity of children who had diarrhea had already been vaccinated. In Maracaibo, a study with children under five years of age, who had diarrheal syndrome, revealed that $43.6 \%$ of the unvaccinated children and $33.3 \%$ of the vaccinated ones against rotavirus obtained positive result for rotavirus [5].

In Brazil, between 2006 and 2010, it was verified a significant decrease in morbimortality among children under one year of age after the introduction of OHRV. However, on the other hand, among the population of one to four years of age there was no decrease, which may be explained by the only two years of immunity period provided by the vaccine [25].

Furthermore, it is known that other pathogens may be the cause of infant diarrhea. In the city of Honduras, a study determined the enteropathogens associated with acute diarrhea in children aged between six months and five years, and it was identified a statistically significant association with rotavirus infections, but also adenovirus and Cryptosporidium spp. [26]. Thus, only the rotavirus vaccine is not able to reduce diarrhea rates, warning again the need to be promoted, among mothers, the various preventive care of diarrhea proposed in the educational video.

In the presented study, it is noted that the chance of occurrence of diarrhea among mothers who used a bottle in the child's diet, in M1, was 1.60 times higher in CG than in IG. In a survey conducted in Macapá, Brazil, it was also identified that the risk of diarrhea is associated with bottle feeding and its inadequate cleaning. [6]

Regarding the cleaning after use of the bottle, it was found that the majority boiled/scalded them, with an odds ratio for the occurrence of infant diarrhea similar in both groups, in M0 and M1. Moreover, among mothers who washed the bottle only with soap and water, the chance of occurrence of diarrhea in children, in M0, was 1.68 times higher in $C G$ than in IG, with no difference between the odds ratio for the groups in M1. 
Lastly, mothers were asked whether they boiled/ scalded other utensils used in the feeding of the child, such as plate, spoon and cup, and it can be observed that among mothers who did not boil/ scald these utensils, the children presented in $\mathrm{M} 1$, 4.90 times more likely to have diarrhea than in the IG. We must highlight the importance of cleaning the environment where these utensils will be washed, whereas a space devoid of hygiene favors the contamination of utensils.

In a district in Indonesia, with a high prevalence of infant diarrhea, it was observed, in investigation of 274 children aged 12 to 59 months, that there was no statistical significance between where utensils are washed (if indoors or outdoors), how they are washed (with tap water or in a bucket), and the frequency of the changing of the water in the bucket with the occurrence of infant diarrhea. It is worth noting that, in this study, it mentions only the use of water for washing utensils. In addition, the odds ratio for the occurrence of infant diarrhea was only 0.38 times in children who have their utensils washed indoors and 0.14 times in those who have the water in the bucket changed for washing utensils. [7]

It is noted that not only the use of the bottle gives risk to the occurrence of diarrhea, but also its inadequate cleaning, as well as the cleaning of other utensils used in child's nutrition. It is therefore crucial that health professionals, especially nurses, empower mothers for proper wash of all the utensils used in the child's nutrition and the environment where they will be cleaned, so that they feel able to prevent diarrhea in their children.

Given the findings, we observe that the children of mothers from IG had less chances of infant diarrhea, revealing thereby the effectiveness of the educational video "Infant Diarrhea: you are able to prevent."

However, reinforces that only the knowledge of risk factors for diarrhea is not a predictor of behaviors that aim a desirable outcome. Because mothers who believe they can keep their children healthy are more likely to perform preventive behaviors against infant diarrhea, even if they do not have the proper knowledge about the risk factors for this problem [27].

Therefore, educational technologies that have only emphasis on information sharing are not sufficient to behavioral changes as self-efficacy should be considered essential for the application of acquired knowledge. [28]

The study had as limitations: short follow-up of mothers to investigate the occurrence of infant diarrhea and a single application of the educational intervention, which also occurred in an isolated way. Thus, the use of periodic educational interventions should be recommended to motivate continuously everyday practices for the prevention of infant diarrhea, as well as the training of nurses and studies on the use of this educational video.

\section{Conclusion}

The educational video "Diarrhea: you are able to prevent" was effective in promoting the adoption of healthy habits by mothers of children under five years of age, being able to reduce the chances for the occurrence of infant diarrhea.

The educational video "Diarrhea: you are able to prevent" promoted the adoption of healthy habits in the care of children under five years of age, being able to reduce the chances of the occurrence of infant diarrhea in the intervention group, even though it was not observed statistically significant association between the occurrence of diarrhea and the studied variables.

Thus, it is fundamental that health professionals get to know the mentioned video and that it can be a tool that guides the practice of these professionals in preventing infant diarrhea and empowering mothers so that they feel able to also prevent the occurrence of this disease in their children. 


\section{Conflict of interest}

The authors declare that they have no conflict of interest.

\section{References}

1. Mamo, A. and Hailu, A. Assessment of Prevalence and Related Factors of Diarrheal Diseases among Under-Five Year's Children in Debrebirehan Referral Hospital, Debrebirehan Town, North Shoa Zone, Amhara Region, Ethiopia. Open Access Library Journal. 2014: 1:1-14

2. World Health Organization (WHO). Ending Preventable Child Deaths from Pneumonia and Diarrhoea by 2025: The integrated Global Action Plan for Pneumonia and Diarrhoea (GAPPD). Geneva: WHO; 2013

3. Paz, M.G.A., Almeida, M.F. and Gunther, W.M.R. Diarrhea in children and sanitation and housing conditions in periurban areas in the city of Guarulhos, SP. Rev. bras. Epidemiol. 2012; 15:188-97

4. Bener, A., Ehlayel, M.S. and Abdulrahman, H.M. Exclusive breast feeding and prevention ofdiarrheal diseases. A study in Qatar. Rev. Bras. Saúde Matern. Infant. 2011; 11: 83-7.

5. Atencio, R., Bracho, A., Porto, L., Callejas, D., Costa, L., Monsalve, F. et al. Síndrome diarreico por rotavirus en niños menores de 5 años inmunizados y no de la ciudad de Maracaibo, estado Zulia, Venezuela. Kasmera, 2013; 41: 59-68

6. Porcy, C., Ferro, T.A.F., Monteiro, S.G., Menezes, R.A.O., Barbosa, F.H.F. and Monteiro Neto, V. Epidemiologia da doença diarreica associada às Escherichia coli diarreiogênicas em crianças residentes em uma área alagada de Macapá - Amapá, Brasil. Ciência Equatorial. 2013; 3:57-68.

7. Agustina, R., Sari, T.P., Satroamidjojo, S., Bovee-Oudenhoven, I.M.J., Feskens, E.J.M. and Kok, F.J. Association of food-hygiene practices and diarrhea prevalence among Indonesian young children from low socioeconomic urban areas. BMC Public Health. 2013; 13:1-12.

8. Cervera, D.P.P., Parreira, B.D.M. and Goulart, B.F. Health education: perception of primary health care nurses in Uberaba, Minas Gerais State. Ciênc. saúde coletiva. 2011; 16:1547-54.

9. Caruso, B., Stephenson, R. and Leon, J.S. Maternal behavior and experience, care access, and agency as determinants of child diarrhoea in Bolivia. Rev. Panam Salud Publica. 2010; 28:429-39.

10. Moraes, A.F. Cultural diversity in health-related videos. Interface. 2008; 12:811-22.

11. Barbosa, R.M. and Bezerra, A.K. Validation of an educational video for the promotion of attachment between seropositive HIV mother and her child. Rev. bras. enferm. 2011; 64:328-34.
12. Banik P. A study to evaluate the effectiveness of video assisted teaching programm on knowledge and practice regarding prevention and home management of dehydration among the mothers of under five children in a selected rural area of Bangalore [dissertation]. Bangalore: Rajiv Gandhi University of Health Sciences; 2012.

13. Desta, B.F., Mohammed, H., Barry, D., Frew, A.H., Hepburn, K. and Claypoole, C. Use of Mobile Video Show for Community Behavior Change on Maternal and Newborn Health in Rural Ethiopia. J Midwifery Womens Health. 2014; 59:S65-72.

14. Weinstein, P., Milgrom, P., Riedy, C.A., Mancl, L.A., Garson, G., Huebner, C.E. et al. Treatment fidelity of brief motivational interviewing and health education in a randomized clinical trial to promote dental attendance oflow-incomemothers and children: Community-Based Intergenerational Oral Health Study "Baby Smiles". BMC Oral Health. 2014; 14.

15. Joventino ES. Elaboração e validação de vídeo educativo para promoção da autoeficácia materna na prevenção da diarreia infantil [tese]. Fortaleza: Departamento de Enfermagem; Universidade Federal do Ceará; 2013.

16. Fortaleza, Secretaria Municipal de Saúde, Célula de Vigilância Epidemiológica/CIEVS/SIMDA. Consolidado das notificações de casos de diarreia aguda por Secretaria Executiva Regional. Fortaleza; 2013. Available in: http://tc1.sms.fortaleza.ce.gov. br/simda/notifica/graficoSerano $=2012 \&$ ser $=$ \&agravo=A09. Accessed: 21 jan 2013

17. Arango HG. Bioestatística: teórica e computacional. Rio de Janeiro: Guanabara Koogan; 2009.

18. Joventino ES. Desenvolvimento de escala para mensurar a autoeficácia materna na prevenção da diarreia infantil [dissertação]. Fortaleza: Departamento de Enfermagem; Universidade Federal do Ceará; 2010.

19. Organização Mundial da Saúde. Mortality Country Fact Sheet 2006. Avaliable in: http://www.who.int/whosis/mort/profiles/ mort searo idn indonesia.pdf. Acess in: 30 de sep. 2009.

20. Bandura, A. Self-efficacy: toward a unifying theory of behavioral change. Psychol. Rev. 1997; 84:191-215.

21. Joventino, E.S., Penha, J.C., Ximenes, L.B., Castro, R.C.M.B., Gomes, A.L.A. and Almeida, P.C. Effect of educational video about maternal self-efficacy and occurrence of childhood diarrhea: randomized clinical trial. Indian Journal of Applied Research. 2015; 5:688-92. 
22. Melli, L.C.F.L. and Waldman, E.A. Tendência temporal e desigualdades na mortalidade por diarreias em menores de 5 anos. Arch. Pediatr. Urug. 2011; 82:39-46.

23. Sousa, G.R.S., Oliveira, E.A.R., Lima, L.H.O., Silva, A.K.A., Formiga, L.M.F. and Rocha, S.S. Profile of children with diarrhea in a public hospital. Rev Enferm UFPI. 2013; 2:34-9.

24. Nascimento, L.A., Rodrigues, A., Joventino, E.S., Vieira, N.F.C., Pinheiro, P.N.C. and Ximenes, L.B. Validation of Educational Video to Promote Self-Efficacy in Preventing Childhood Diarrhea. Health. 2015; 7:192-200.

25. Oliveira, J.F., Amaral, J.B., Oliveira, K.F. and Gonçalves, J.R.L. Evaluation of the impact of oral vaccine against human rotavirus in Brazil. REAS. 2014; 3:107-15.

26. Arima, Y., Kaminsky, R.G., Montes, G.A.Á., Casiano-Colón, A., Guthrie, B.L., DiGiacomo, R.F. and Jacobs, J. Nuevos y viejos agentes asociados a diarrea en niños en honduras. Rev. méd. hondur. 2011; 79:58-64.

27. Liu, J. Maternal beliefs and behaviors in the prevention of childhood diarrhea in Dares Salaam, Tanzania [thesis].Program in Human Biology Honors Thesis; Stanford University; 2009.

28. Morgado, M.V., Pires, A. and Pinto, J.R. Self-efficacy in asthmatic children. Psic., Saúde \& Doenças. 2000; 1:121-28.

Publish in International Archives of Medicine

International Archives of Medicine is an open access journal publishing articles encompassing all aspects of medical science and clinical practice. IAM is considered a megajournal with independent sections on all areas of medicine. IAM is a really international journal with authors and board members from all around the world. The journal is widely indexed and classified Q2 in category Medicine. 